\title{
UTOPIA E COLONIZAÇÃO (*).
}

\author{
MARCEL BATAILLON \\ (Professor do Colégio de França).
}

Quando nos interrogamos sobre o que foi que o humanismo do século XVI construiu de mais oposto à concepção do Príncipe de Maquiavel, é-nos licito hesitar entre o ideal do Príncipe cristão segundo Erasmo e o ideal da República utopista segundo Thomas More. No entanto, rapidamente nos apercebemos que a monarquia do príncipe cristão e a do Príncipe de Maquiavel se opõem como duas concepções políticas análogas, animadas embora de espíritos bem diferentes. Ao lermos, no Diálogo entre Mercúrio e Caronte do erasmista espanhol Alfonso de Valdés, a autobiografia do bom rei Polydoro, deparamos com uma passagem da tirania a uma monarquia cristã que mais não é do que uma conversão, como quem põe do lado direito uma roupa que estava do avesso. Uma iluminação divina transforma o mau pastor no Bom Pastor dos seus povos. Assim, despotismo esclarecido e monarquia iluminada pelo espírito evangélico podem apresentar analogias profundas na medida em que são duas estruturas tendo por chave de abóbada um chefe providencial. A este propósito, Eugênio Massa focalizou recentemente o significado messiânico do Príncipe segundo Maquiavel, a sua missão de único realizador do Bem no seio de uma humanidade totalmente perversa.

Muito mais radical se nos afigura a oposição entre o governo do Príncipe - seja ele guerreiro ou pacífico, quer faça apelo ao temor ou ao amor dos seus povos - e a República utopista fundada sobre a igualdade perante a lei' e sobre a comunidade dos bens. A relação

(*). - Este texto de Marcel Bataillon foi redigido em 1949 para um colóquio realizado nessa data em Roma e Florença sobre o tema Humanismo e Ciência Política, não tendo sido eventualmente inserido nas Atas desse colóquio. Foram estas publicadas pelo Arquivo de Filosofia da Universidade de Roma sob o título Humanismo e Maquiavelismo. Tradução de Margàrida Barradas de Carvalho (Nota da tradutora). 
que Massa estabelece entre a concepção pessimista da humanidade pervertida pelo pecado original e o absolutismo do Príncipe podemos acha-la, embora atenuada, entre essa mesma concepção cristã fundamental e o paternalismo do Príncipe cristão. Ao invés, a Utopia, quaisquer que possam ser os preconceitos cristãos do seu autor, irradia confiança na razão e na soberania desta sobre os homens. Dir-se-ia, quando a lemos, que a humanidade tem a capacidade de reformar, pela razão, os seus fins e os seus meios, de ascender a um hedonismo superior, segundo o qual a prática da virtude e do altruismo propiciaria o mais exaltante dos prazeres. E, alem de tudo, a Répública utopista opõe-se a toda e qualquer monarquia ideal pelo seu socialismo fundamental, pela sua preocupação de prover às necessidades de todos, reduzindo o fardo do trabalho de cada um a seis horas por dia, pela sua tendência a dar a prioridade ao aspecto econômico, como se a boa administração das coisas materiais fosse, pelo menos, a metade da tarefa do governo dos homens.

Se a concepção do Príncipe cristão tem, não obstante, algo que a aproxima da República de More, se já foi muitas vezes apelidada de utópica em contraposição à do Príncipe de Maquiavel, isso é devido ao fato que o seu poder pacífico e paternalista parece exigir dos governantes e dos governados virtudes superiores às do comum dos homens e que conta, expressamente, com o auxílio da graça divina. E do conhecimento geral que Utopia, de nome próprio passou a nome comum. De utópico, com intenção pejorativa, designam os políticos que se pretendem realistas todo o ideal que se lhes afigura irrealizavel, o qual, quando muito, pode constituir um objectivo ambicionado. A Utopia de More tem sido geralmente considerada como a expressão desse ideal. Guillaume Budé, um dos raros humanistas sensíveis à sua fecunda originalidade, destaca precisamente o interesse da República de More, como sendo uma sementeira de idéias e de instituições que seria preciso adaptar para as transplantar no seio dos Estados existentes.

No quadro da ciência política renovada pelo humanismo, ainda não tem lugar um fato que entrou há uma dúzia de anos na história da América colonial: a saber, que a república utopista de More fora considerada como facilmente adaptavel às necessidades da Nova Espanha, isto é, do México, ocupado, havia doze ou quinze anos, pelos conquistadores. Trata-se, com efeito, de uma sugestão apresentada ainda em vida do próprio Thomas More. Enquanto que os humanistas cristãos da roda de Carlos Quinto se deliciavam com o ideal do Príncipe cristão e se gabavam de o ver posto em prática pelo seu Senhor à escala da Europa, o magistrado humanista Dom Vasco de Quiroga, instalado na Audiência do México, já propusera instalar os índios des- 
se pais em cidades organizadas à maneira da Utopia. Perdeu-se, infelizmente, a memória na qual ele expunha, detalhadamente, o seu projecto. Apenas se descobriu um "Relatório jurídico" (Información en derecho) dirigido por ele do México ao Conselho das Indias, e datado, por uma patética coincidência, de 24 de julho de 1535 , menos de três semanas após a execução de Thomas More, em Londres. E um grito de alarme lançado contra uma nova medida que permitia reduzir os índios à escravatura. E é tambem um copioso tratado, mais longo do que a Utopia, simultaneamente crítico e construtivo, no qual Quiroga faz numerosas referências ao seu Aviso (Parecer) anterior. Assim se revela em grande parte o segredo deste homem extraordinário que chega ao México com sessenta anos na qualidade de Auditor do Supremo e que, nessa altura, descobre em si uma vocação de protetor et de apóstolo dos índios; o qual, por ser laico, é ordenado de propósito a fim de poder assumir o cargo de bispo em Michoacán - como Santo Ambrósio que de laico passara a bispo de Milão; que vive até aos noventa e cinco anos para os seus fieis; e que deixa de si a lembrança dum santo, dum legislador, dum mestre das populações nativas. Em Uruapán, onde faleceu, diz-se que a cultura da bananeira e a indústria sempre viva das xícaras (jícaras), ou malgas lacadas à maneira chinesa, foram introduzidas por Quiroga. Os tarasques ainda hoje veneram a memória de "Tata Quiroga", especialmente no lugar de Santa Fé, fundado por ele nas margens do lago Pátzcuaro como um hospício, isto é, um refúgio para os índios.

Dom Vasco, ainda quando magistrado, fundara entre $1530 \mathrm{e}$ 1534 os dois refúgios ou hospícios de Santa Fé, um às portas da cidade de México, outro às portas de Tzintzuntzán, a antiga capital do Michoacán. Mais tarde, redigira para eles uma espécie de regulamento ou de constituição. O texto, incompleto, foi encontrado no século XVIII. Por ele se deduz que as duas aldeias de Santa Fé, dotadas de terras graças à generosidade do seu fundador, tinham sido concebidas, ou pelo menos sonhadas, por ele, como comunidades indígenas vivendo da agricultura, tendo cada habitante a obrigação de trabalhar seis horas diárias para a república, e devendo essas comunidades ser administradas por magistrados nativos eleitos, sob o controle de um reitor eclesiástico espanhol. Deveriam outrossim satisfazer todas as necessidades temporais e espirituais dos seus membros.

O descobrimento da Información en derecho, tão insistente nas suas referências a um projecto de organização mixta (policía mixta), simultaneamente temporal e espiritual, dos indígenas mexicanos, tão entusiasta nos seus elogios a Thomas More, inspirador do sistema, veio renovar a interpretação do pensamento de Quiroga. Permitiu ao his- 
toriador mexicano Sílvio Zavala mostrar em 1937 que o regulamento dos dois pueblos de Santa Fé era o de duas Utopias em miniatura e que o ideal de Thomas More animava toda a obra do Auditor Quiroga, primeiro bispo de Michoacán, todo o seu esforço para instaurar uma nova Cristandade neste novo mundo.

Desde então, em 1941, Sílvio Zavala deu a conhecer um exemplar da Utopia pertencente, não a Quiroga, mas ao franciscano seu amigo, Fr. Juan de Zumárraga, primeiro bispo do México, outra grande figura de apóstolo. E recentemente, em 1948, o espanhol Juan Antonio Maravall marcou a persistência através de todo o século XVI, do que chamou a "utopia político-religiosa" dos franciscanos da Nova Espanha. E essencialmente a idéia de uma sociedade cristã de indígenas subtraida às leis da velha Europa filha do direito romano; de uma sociedade nova, tendo com os espanhois que nela exercem a soberania o menor número possivel de relações, vivendo material e espiritualmente sob a tutela dos religiosos. Algo assim que faz lembrar, em suma, o que os jesuitas realizariam mais tarde no Paraguay.

Esta concepção assenta na idéia fundamental de que as populações do Novo Mundo vivem num estado de quase-inocência, o que permite fazer delas cristãos mais autênticos do que os velhos cristãos da Europa. Os atuais historiadores da América comprazem-se em dizer que aí podemos vislumbrar o aparecer do que se chamará, na ideologia otimista do século XVIII, o mito do bom selvagem. E Maravall insiste no otimismo ingênuo, sistemático (utópico no sentido vulgar do termo) da utopia franciscana. A utopia de Quiroga, como a dos franciscanos, repousa com efeito numa visão contrastada da humanidade, otimista em relação aos homens do Novo Mundo, pessimista em relação aos do Velho. Esta visão não é, porem, ao fim e ao cabo, mais halucinada do que o pessimismo absoluto que se deduz do pecado original. Resulta de uma observação sumária, pré-científica, do constraste entre aquilo que os etnólogos de hoje designariam como populações evoluidas e populações primitivas. O meu intuito é mostrar que a utopia do piedoso fundador dos Hospícios de Santa Fé não é utópica no sentido banal de inadaptada à realidade.

Grave erro seria o de julgar que o entusiasmo desse ancião pela Utopia de More significa que ele queria vive-la como Dom Quixote quer viver os romances de cavalaria, sem se aperceber de tudo quanto à sua roda a contradiz. Ao lermos a Información en derecho, sentimo-nos, sem dúvida, em presença de um magistrado humanista, e moralista tambem, e familiarizado com os Padres da Igreja, mas contudo de um magistrado que não renegou o direito espanhol, nem o direito 
romano. O seu longo relatório está repleto de discussões jurídicas das mais pertinentes. Por outro lado, faz-nos pensar tambem na elaboração de um novo direito para uma situação sem precedentes. Quiroga extasia-se, realmente, ao encontrar em More, e situada como por acaso nas Ilhas recem-descobertas, uma humanidade simples, ingenuamente razoavel, vivendo segundo a natureza, desprovida das necessidades que os europeus criaram para si próprios e que freneticamente os agitam. A humanidade utopista é bem irmã, mas uma irmã civilizada, da do Novo Mundo. Este mundo é novo, explica Quiroga, não só pela data da sua abertura aos europeus, mas tambem pela juventude absoluta das suas populações. Aqui toma sentido o mito da Idade de Ouro. Não fica Quiroga menos maravilhado ao encontrar o paraiso poético dos "Saturnia regna", nos Saturniales de Luciano, onde talvez, supõe ele, More se tenha inspirado. Há um mundo real ao qual se ajustam, em certa medida, estes ideais. $\mathbf{E}$ foi decerto por inspiração divina, sem outra base alem do relato de Américo Vespúcio, que More colocou no longínquo Ocidente esta república razoavel cujas leis regem uma humanidade criança, desinteressada, despreocupada, indolente. Utopia é um pais de vida sensata, natural, facil, não é um pais de Cocanha onde a abundância reinaria por dom gratuito do Céu, nem tão-pouco um paraiso povoado de puros espíritos ignorando todo e qualquer constrangimento. Com a lei das seis horas diárias de trabalho, com um direito penal que substitui a pena de morte pelo trabalho forçado, a vida econômica e social fica estabelecida sobre uma base sólida. More fizera praticamente abstracção da fé cristã, sugerindo, como acertadamente foi dito, por um juizo a fortiori, que o Cristianismo e a graça tornscriam facil uma organização social demonstradamente possivel sobre o terreno da simples razão e da religião natural. Quando muito, expressara a idéia que os habitantes de Utopia (os Utopienses), em contacto com o Cristianismo, mostravam por esta religião um maravilhoso pendor. A Utopia, repensada para uso dos mexicanos pelo seu evangelizador, estabelece a vida comunitária daqueles sobre a dupla base do trabalho e do culto cristão. Deste modo, torna-se uma organização mixta (policía mixta), simultaneamente temporal e espiritual, unica solução, no entender de Quiroga, ao problema urgente posto pela presença dos espanhois no pais.

Longe de ser uma construção sem bases realistas, a Utopia de Quiroga vai ao encontro da realidade, da mais terrivel realidade. $\mathbf{O}$ Novo Mundo não fora descoberto por exploradores desinteressados. E menos ainda por reformadores sociais em busca, como Cabet, de uma terra virgem onde os europeus emigrados poderiam fundar uma sociedade justa, liberta das tradiçōes da propriedade tentacular e da 
exploração do homem pelo homem. A terrivel realidade que o nosso utopista pretende combater, é o fato colonial em toda a sua crueza, a escravidão dessas populações inocentes, precipitadas da sua idade de ouro numa idade de ferro, condenadas aos trabalhos forçados do transporte e das minas, ou seja, à morte a curto prazo. E a mesma situação que Las Casas, esse outro bispo, apóstolo do México e do Guatemala, resumiu sob a expressão acusadora de destruição das Indias. Quiroga não é mais indulgente do que o bispo de Chiapas quanto aos processos dos conquistadores. Esses apóstolos mostram-nos os seus aventurosos compatriotas dominados pela paixão do poder e da cobiça, jogadores, luxuriosos, lançados sem freio na cata do ouro e das mulheres, destruindo com a mais perfeita inconsciência o capital humano de que se apossam e que não podem dispensar.

Quiroga considera como um fato tristemente consumado a destruição das Ilhas e da Terra Firme, isto é, o despovoamento irremediavel de São Domingos, de Cuba, das Antilhas e da região costeira da Venezuela. Não foram precisos quarenta anos para atingir tão funesto resultado. No México, onde os espanhois entraram somente há quinze anos, em busca do metal precioso, o mal está menos avançado, ainda é remediavel. Notam-se já, sem dúvida, os efeitos da exploração, mas tambem os primeiros frutos da evangelização. Uns e outros são reveladores de dois destinos possíveis para as populações estranhamente dóceis da Nova Espanha. Ou a escravidão e a morte dos indígenas, se não for instaurada uma organização apropriada, e para os espanhois o crime inexpiavel de ter devastado um mundo novo cheio de promessas; ou então, se se souber cristianizar e civilizar esses povos crianças, ter-se-á plantado aqui uma nova Cristandade, segundo a vontade de Deus, como uma desforra ou um renascimento da velha Igreja do Velho Mundo.

Quiroga é um homem de ação, de quem não se deve esperar teorias gerais sobre a conquista e a colonização de povos mais primitivos por povos melhor armados e apetrechados. A maneira, porem, de invocar o discurso do camponês do Danúbio e de o comparar com o comovente discurso dos chefes do Michoacán, oferecendo as suas pessoas como refens para que as suas vidas, ou a sua liberdade, sejam uma garantia do desejo de paz dos seus compatriotas, tudo isso implica uma doutrina, não evidentemente do direito dos povos disporem de si próprios, mas do dever que aos povos mais civilizados incumbe em não trazerem aos mais primitivos a guerra e a escravatura, quer os conquistadores se chamem Roma ou Espanha. Esse extraordinário documento que é a Información en derecho contem um aviso solene contra uma disposição recem-extorquida ao Conselho das Indias pelos 
conquistadores, permitindo a estes declararem escravos os índios, seja os que fossem capturados na guerra, seja os que tivessem sido comprados por eles a outros índios como já sendo escravos destes. A coberto destas duas categorias - escravos de guerra e escravos de resgate - os conquistadores, em busca de mão-de-obra servil, terão artes, se os deixarem, de escravizar toda a população indígena. De qualquer das maneiras, a iniquidade será monstruosa. Não há propriamente guerra entre os conquistadores e essa população indefesa que eles acusam de rebeldia: é como um homem que, querendo afogar o seu cão, diga que este tem raiva. Dão-lhes caça e consideram a sua fuga como um ato de resistência, e tudo isso porque precisam, a qualquer preço, de escravos para as minas. Os pretensos escravos de guerra não são mais do que vítimas da rapina. Quanto aos escravos de resgate, serão vítimas duma inqualificavel falsificação jurídica. Um escravo cristão cativo dos infieis pode muito bem ser resgatado por outro cristão. Mas o direito romano não admite que este se torne proprietário do resgatado. Este, de volta a terras cristãs, fica livre, apenas sob o compromisso de recompensar o resgatante quer em dinheiro, quer em trabalho avaliado consoante o preço pago. E o jus postliminii, que fixa em cinco anos de trabalho servil, no máximo, o equivalente em trabalho do resgate, se este não puder ser pago em dinheiro. Há, pois, nesta nova regulamentação que baptiza de esclavos de rescate escravos comprados como se fossem gado, um abuso inadmissivel da noção de resgate.

Nesta defesa dos indígenas, Quiroga não se serve apenas da sua ciência do direito espanhol e romano. Serve-se tambem dos seus novos conhecimentos do direito indígena, adquiridos por ele e pelos seus colegas no exercício das suas funçб̋es de juizes. Muito embora um índio possa ser declarado escravo pelo dono que o vende a um espanhol; e mais, embora o próprio possa declarar-se escravo do seu dono, não haverá nisto mais do que um abuso de linguagem. No império azteca, o que acontece normalmente (fora uma ínfima minoria de escravos de guerra votados aos sacrifícios humanos) é uma espécie de servidão voluntária e vitalícia, distinta da escravidão: um índio miseravel vende habitualmente o seu trabalho, a troco de milho para o seu sustento, a um índio rico, ou folgado, da vizinhança; servi-lo-á até à morte, mas não será por esse fato arrancado à sua cabana e à sua família, não se tornará por esse fato uma coisa de que se pode fazer negócio. E dificil saber até que ponto esta descrição se ajusta à realidade. Mas temos que admirar, em todo o caso, a repugnância que o nosso utopista manifesta em relação à escravatura. Repugnância de jurisconsulto humanista, por um lado. Por outro, o sentimento do evangelizador preocupado em plantar no Novo Mundo uma nova 
Cristandade e que não pode tolerar que sejam marcadas com os ferros da escravatura as faces de homens criados à imagem de Deus, que seiam tratados como "réprobos" seres beneficiários, como todos os homens, da redenção pelo sangue de Cristo.

Como alternativa à degradação, à destruição, propõe a Utopia salvadora: uma organização razoavel. $O$ dito realismo político não pode descartar-se desta utopia com um encolher de ombros, dizendo: "mito do bom selvagem, miragem infantil!". Na realidade, esses homens da idade de ouro do Novo Mundo não nos são apresentados como sendo dotados de todas as virtudes. Quiroga, pensando sobretudo nos mais miseráveis, na massa dos macehuales, vê neles cristãos em esperança, porque são simples, dóceis, porque têm poucas necessidades, sendo por isso desprovidos de soberba e de cobiça, essa terrivel codícia, raiz de quase todos os vícios europeus. Os vícios deles nascem da indolência, reverso da feliz despreocupação que os torna tão permeáveis ao Evangelho. Precisam de ter uma disciplina de trabalho, embora disfrutem da sorte de viver num pais clemente, onde certas plantas, como o milho e o "maguey", sem contar as árvores frutíferas, lhes fornecem o necessário com um mínimo de esforço, e onde as plantas úteis e os animais domésticos da Europa se podem facilmente aclimatar. Por outro lado, estes homens têm o sentido do sagrado. E com facilidade que passam a votar aos religiosos cristãos a veneração supersticiosa que votavam aos seus chefes idólatras e a Deus o culto que prestavam aos seus ídolos. Não se pode negar que as suas festas, as suas danças, são acompanhadas por desordens frenéticas, por ebriedades funestas à decência e à razão. Os que moram dispersos ignoram até qualquer decência. Em suma, o que se depreende é que, para Quiroga, a sua extrema docilidade torna insignificantes os aspectos negativos do seu estado natural. A fé do utopista reside, não na natureza, mas antes na educação e no Evangelho. Dá grande importância à sociabilidade, mas a uma sociabilidade que será preciso praticamente criar, ou, pelo menos, elevar no nivel instintivo ao nivel político.

Quando um Polo de Ongardo for transplantado ao Perú, achará inúmeros motivos de admiração nas instituições indígenas, nesta organização racional dos Incas, a qual, mais tarde, idealizada pelo inca Garcilaso, se tornará no século das luzes um grande argumento contra a tirania obscurantista dos espanhois. Tais tendências não se encontram em Quiroga. Para ele, é justamente a organização política e social, a policía, como ele diz, o que falta aos indígenas da Nova Espanha, sobretudo aos mais primitivos, aos mais dispersos, justamente os que mais facilmente se tornam vítimas da miséria e da opressão pelo seu próprio isolamento. De um modo geral, a organização nativa 
parece-lhe opressiva e bárbara. Quando a confronta com a classificação de Gerson, tirada de Aristóteles, não vê nela nem realeza, nem aristocracia, nem timocracia dignas destes nobres títulos. $O$ que lhe parece haver é um mixto das suas formas degeneradas que são a tirania, a oligarquia, a democracia anárquica. No entanto, admira o reto senso, as boas razões, com os quais estes primtivos são capazes de defender a sua causa. Discípulo de More, admira a sua tendência em eleger os caciques, em vez de correr os riscos duma transmissão hereditária, em linha reta, do poder. Vê nisso os germes de uma sociedade racional utilizáveis por uma policía preocupada em conciliar o interesse individual e o coletivo, e em confiar os negócios da coletividade aos mais aptos. E, em suma, uma organização municipal, com cargos electivos, que Quiroga concebe na sua utopia decalcada sobre a de More.

Não se trata aqui de analisar detalhadamente este programa, tanto mais que nos falta a base imprescindivel, isto é, o Parecer, onde ele vinha sistematicamente exposto. Mas impõem-se alguns traços pelo vigor com que Quiroga os acentua na sua Información, como respondendo, não a um ideal abstracto, mas a uma necessidade vital. E antes de tudo, o reagrupamento em cidades. O humanista cristão compraz-se em invocar esta opinião do pseudo Santo Cirilo, de que as cidades realizam uma comunidade de serviços, permitindo aos homens não só viver, mas viver em paz. Uma das idéias fixas deste homem que conheceu diversas populações índias, desde o Anáhuac até - Michoacán, é que a miséria e a barbárie são os efeitos normais da dispersão. Imagina ele grandes cidades, como as da Utopia, agrupando até 60.000 adultos. Esta concepção é tanto mais surpreendente quanto que, à primeira vista, para ele como para More, o fundamento duma economia sã é a agricultura. O paradoxo atenua-se na medida em que levarmos em conta que, nestas utopias comunitárias, o trabalho agrícola é um serviço social, e não a exploração de domínios aos quais as famílias estejam ligadas de geração em geração.

O agrupamento em cidades oferece uma vantagem em relação ao problema preciso que Quiroga pretende resolver. Uma cidade de 60.000 adultos não precisa, para controlar os responsáveis indígenas da presença senão de um "corregidor" espanhol. Do mesmo modo, bastará um pequeno número de religiosos para aí administrar o ensino e os sacramentos do Cristianismo, o que permitiria ser mais exigente quanto à qualidade dos evangelizadores. Em suma, tanto no temporal, como no espiritual, o aparelho espanhol será reduzido a um mínimo. Encontramos aqui a aplicação do princípio fundamental de que os espanhois devem ficar separados o mais possivel dos indígenas, para 
que estes novos cristãos não tenham sob os olhos os exemplos deploráveis dos conquistadores, que os escandalizam e minam a sua fé nascente, mostrando-lhes uma conduta oposta a todas as virtudes que lhes são apregoadas. Na policía imaginada para os índios, os espanhois só assumem a função sacerdotal, a suprema direcção e a defesa, se é que esta defesa não é assegurada em últịma instância por Deus. Pois trata-se de uma obra de Deus, de um crescimento e de um rejuvenescimento do corpo místico da Cristandade, acontecimento capital, inconcebivel sem uma vontade divina. A única justificação da presença dos espanhois nesta Nova Espanha, é a bula do Papa, dando-lhes por missão a sua cristianização. Quiroga, ainda quando era laico pregara aos povos do Michoacán que havia apenas um Deus no céu, e na terra um só soberano, o Imperador. Carlos-Quinto é, ao mesmo tempo, o rei e o apóstolo máximo. Tal é o fundamento da policía mixta, simultaneamente espiritual e temporal, e que constitui a principal novidade da Utopia de Quiroga em relação à de More.

Ainda há outra, e importante, decorrente do fato de que os planos de Quiroga são, como mostramos, uma solução humana ao drama colonial. A Utopia de More era uma república independente, eventualmente migratória e colonizadora. A policía que convem aos indígenas do México é um sistema a ser instaurado autoritariamente num pais colonizado. Quiroga não cai na ingenuidade de crer que os espanhois vindos às Indias em busca de fortuna são suscetíveis de renunciar aos seus projectos. Trata-se, ao defender os índios contra os conquistadores, de defender os interesses destes últimos contra si próprios, de os impedir de matar a galinha dos ovos de ouro. A lei das seis horas, transplantada da Utopia para a Nova Espanha, seria como um compromisso entre a preguiça natural dos índios e a avidez insaciavel dos recem-chegados. E preciso, diz expressamente Quiroga, impedir que os índios morram de miséria para alimentar o nosso fausto, a nossa soberba, as nossas despesas que esmagam homens tão pobres e tão débeis: organizados no quadro de uma policía protetora, alem de se instruirem e de se cristianizarem, poderão tambem alimentar-se e alimentar os espanhois. O trabalho obrigatório moderado substituirá o ócio pela atividade industriosa. Acarretará uma elevação moral dos índios; e estes, sem perder a sua docilidade e simplicidade de vida, acabarão por produzir muito alem das suas poucas necessidades, provendo assim aos encargos gerais, incluindo o aparelho espanhol, incluindo o próprio imposto exigido implacavelmente pelos conquistadores privilegiados. Temos de reconhecer que, no quadro férreo da colonização, era dificil ser mais fiel ao espírito de More, ao seu cuidado de organizar uma comunidade de produtores, onde o trabalho, sendo uma lei, não seja uma escravidão. 
Finalmente, uma última interrogação se nos impõe. Acreditou Quiroga totalmente na organização que preconizava, ao ponto de querer demonstrar essa possibilidade fazendo aplicações parciais - como diríamos hoje, experimentais? Para nós, a Utopia é o pais de nenhures. Para Quiroga, o gênio de More consiste em no-la apresentar como um pais que existe algures; não como uma concepção do espírito, mas como uma coisa vista: "ponerla, contarla y afirmarla por cosa vista y hecha y experimentada". Tal sociedade, acrescenta ele ainda, pode parecer incrivel a quem não tenha dela experiência, "mas quem teve essa experiência não duvidará um só instante da sua possibilidade". Ao lermos estas afirmações, é dificil não supor que Quiroga se refere ao seus pueblos-hospitales de Santa Fé. Na realidade, pensa numa experiência mais vasta e mais difusa. Propomo-nos mostrar, noutro lado, o alcance de um primeiro projeto de pueblos de neófitos, ao qual se dedicou ardentemente. É preciso defendermo-nos da tentação de o considerar como um ideólogo que, tendo descoberto na Utopia a panacéia da América colonial, e instalado dois falanstérios, os propusesse ao poder como dois modelos reduzidos em vista de realizações mais grandiosas.

O que nos surpreende quando lemos as Ordenanças redigidas muito tarde pelo fundador para as duas aldeias-refúgios, são, evidentemente, as numerosas reminiscências da Utopia, mas são tambem as muitas recomendações em relação à lei das seis horas, o que nos faz duvidar bastante da medida em que ela foi respeitada e vivida dentro dos costumes dessas pequenas coletividades já velhas de um quarto de século. Antes se diria que o bispo Quiroga, no fim da sua carreira episcopal, procura consolar-se de não ter visto a realização da sua policía mixta inspirada de More, legando o seu ideal aos dois Hospitales fundados por ele. $\mathrm{E}$, de fato, não sabemos em que medida eles o aplicaram. Dispomos sobre os Hospitales nascentes, tais como eram em 1535, no tempo da Información en derecho, de um precioso acervo de testemunhos, que respondem ao inquérito administrativo levado a cabo sobre a gestão do magistrado Quiroga, na altura em que deixou o seu cargo. Inúmeras testemunhas celebram os benefícios que essas fundações trouxeram aos índios miseráveis, salvando-os materialmente; ainda mais insistem sobre a vida religiosa dessas comunidades, onde os índios não só ouvem a missa, como cantam os ofícios. Nem uma só se refere à admiravel novidade que seria uma pequena república de índios, administrada pelos seus eleitos sob a tutela de um reitor espanhol. Escutemos o bispo Zumárraga, tambem leitor de More, e uma das testemunhas que definem a instituição das aldeias-hospícios como um grande refúgio para os índios no temporal, como no espiritual. Dá-nos este detalhe precioso sobre os efeitos da 
inspecção e da declaração de paz do auditor Quiroga no Michoacán. Enquanto que, antes da sua passagem, as missões tinham falhado inteiramente, após ela, já se tinham fundado cinco ou seis mosteiros que funcionavam à maravilha. Os progressos eram diários, tanto em cristianização como em civilização ("en la cristianidad y policía"). Em volta desses lares naturais, os nativos "curtem o couro, fabricam sabão, selas de cavalos, as armações em pau das selas e das albardas, e outras coisas com as quais ganham a sua vida". Reparemos que todos os produtos indicados são destinados aos espanhois. Estabelece-se assim uma simbiose no lugar de uma opressão destruidora.

Quiroga refere-se, evidentemente, muito mais a este tipo de experiência humana do que a uma aplicação literal das leis da Utopia num domínio restrito. Oferecer a paz, trazer, ao mesmo tempo, a revelação cristã e os ofícios a populações facilmente atraidas; juntar nas aldeias-refúgios os miseráveis acossados, que ali podem ver a prática simultânea dos ritos e das obras de misericórdia de uma religião na qual, doravante, podem acreditar, tal é, aos olhos de Quiroga a base experimental suficiente para demonstrar o benefício de uma policía mixta, à qual se adaptariam maravilhosamente as leis da Utopia. Diversas vezes, dá a entender que o único mérito das soluções propostas por ele é o de poderem orientar o legislador competente (mittere sapientem in viam) e o de se basearem na experiência de um homem, cujo testemunho bem vale o dos conquistadores ávidos. Não se trata de um ideólogo que se teria proposto realizar a todo o custo a Utopia, modelando um material humano propício. Dificilmente seria podido sonhar Thomas More uma consagração mais nobre para o seu livrinho do que o destino que lhe reservou esse evangelizador do México.

MARCEL BATAILLON. - Né à Dijon le 20 Mai 1895. Elève de l'École Normale Supérieur en 1913. Officier d'artillerie en 1917. Agregé d'Espagnol en 1920. Prof. à l'Université de Lisbonne en 1922. Au Lycée de Bordeaux en 1926, à l'Université d'Alger en 1929, à la Sorbonne en 1937, au Collège de France en 1945. Professeur et administrateur Honoraire de ce Collège depuis 1965. 